\title{
Correction to: Double Vision Model Using Space-Time Function Control within Silicon Microring System
}

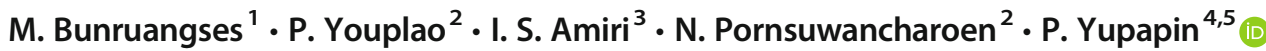

Published online: 18 September 2020

(C) Springer Nature B.V. 2020

\section{Correction to: Silicon}

https://doi.org/10.1007/s12633-019-00356-6

The original version of this article unfortunately contained a mistake in the "Acknowledgments" section. As for an important condition required by the first author's affiliation so that the research project can attain the research grant support, the sentence that acknowledges the first author's affiliation must thus be stated appropriately in the article. The corrected 'Acknowledgments' statement is given below.

Acknowledgments The authors would like to acknowledge the research facilities from Ton Duc Thang University, Vietnam, and Rajamangala University of Technology Phra Nakhon, Bangkok 10300, Thailand.

Publisher's Note Springer Nature remains neutral with regard to jurisdictional claims in published maps and institutional affiliations.

The online version of the original article can be found at https://doi.org/ 10.1007/s12633-019-00356-6

\author{
P. Yupapin \\ preecha.yupapin@tdtu.edu.vn \\ M. Bunruangses \\ montree.b@rmutp.ac.th \\ P. Youplao \\ phichai.yo@rmuti.ac.th \\ I. S. Amiri \\ amiri@bu.edu \\ N. Pornsuwancharoen \\ nithiroth.po@rmuti.ac.th
}

1 Department of Computer Engineering, Faculty of Industrial Education, Rajamangala University of Technology Phra Nakhon, Bangkok 10300, Thailand

2 Department of Electrical Engineering, Faculty of Industry and Technology, Rajamangala University of Technology Isan, Sakon Nakhon Campus, Sakon Nakhon 47160, Thailand

3 Division of Materials Science and Engineering, Boston University, Boston, MA 02215, USA

4 Computational Optics Research Group, Advanced Institute of Materials Science, Ton Duc Thang University, District 7, Ho Chi Minh City, Vietnam

5 Faculty of Applied Sciences, Ton Duc Thang University, District 7, Ho Chi Minh City, Vietnam 